\title{
Perkiraan Lonjakan Jumlah Kunjungan Wisatawan di Kabupaten Toraja Utara Tahun 2021 dengan Penerapan Metode ARIMA
}

\section{Forecasting of Total Tourism Visit in North Toraja Regency in 2021 with Applied of ARIMA Method}

\author{
Bakhtiar $^{1 *}$, Didiharyono ${ }^{2)}$ \\ ${ }^{1,2)}$ Universitas Andi Djemma Kota Palopo \\ Received 20 th July 2018 / Accepted 20 ${ }^{\text {th }}$ September 2018
}

\begin{abstract}
ABSTRAK
Penelitian ini bertujuan untuk memperkirakan (forecasting) lonjakan jumlah wisatawan di kabupaten Toraja Utara tahun 2021 dengan penerapan model ARIMA. Metode penelitian yang digunakan adalah penelitian terapan (applied research) dengan data sekunder kuantitatif yang diperoleh di BPS Kab. Toraja Utara. Prosedur penelitian yang dilakukan meliputi identifikasi model, estimasi parameter, tahap diagnostik dan forcasting dengan bantuan soft komputer dalam hal ini Minitab 18. Berdasarkan hasil penelitian diperoleh lima model time series yang digunakan memperkirakan lonjakan jumlah wisatawan di kabupaten Toraja Utara tahun 2021 yakni ARIMA $(1,1,1)$, ARIMA $(2,1,1)$ dan ARIMA $(1,2,1)$. Kriteria yang tepat dalam pemilihan model yang terbaik adalah model yang mempunyai nilai MS (Mean Square) terkecil. Dalam hal ini model time series dengan MS terkecil adalah ARIMA $(1,1,1)$ yaitu sebesar 16487384. Sehingga, model ini yang digunakan dalam melakukan peramalan adalah ARIMA $(1,1,1)$ dengan bentuk umumnya yaitu $Z_{t}=0,925 Z_{t-1}+0,075 Z_{t-2}+a_{t}-0,9830 a_{t-1}$. Hasil memperkirakan dari bulan januari sampai Desember 2021 adalah 13984,9; 14924,1; 15033,$1 ; 15204,6 ; 15371,4 ; 15538,6 ; 15705,7 ; 15872,8 ; 16040 ; 16207,1 ; 16374,2$ dan 16541,4 .
\end{abstract}

Kata kunci: Forcasting, Jumlah Wisatawan dan Model ARIMA.

\begin{abstract}
This study aims to forecasting spike in the total of tourists in North Toraja district in 2021 with the applied of ARIMA model. The research method used is applied research with quantitative secondary data obtained in BPS Kab. Toraja Utara. The research procedures include model identification, parameter estimation, diagnostic stage and forcasting with used soft computer is Minitab 18. Based on the research result, obtained five time series models are used to forcasting the number of tourists in North Toraja 2021 is ARIMA (1,1,1), ARIMA (2,1,1) and ARIMA (1,2,1). The right criteria in selecting the best model is the model that has the smallest Mean Square (MS) value. In this case the
\end{abstract}

*Korespondensi:

email: bakhtiar647@gmail.com 


\section{Bakhtiar (2018)}

time series model with the smallest MS is ARIMA $(1,1,1)$ is 16487384. Thus, this model used in doing the forecasting is ARIMA $(1,1,1)$ with the general form that's $Z_{t}=$ $0,925 Z_{t-1}+0,075 Z_{t-2}+a_{t}-0,9830 a_{t-1}$. The forcasting result from January to December 2021 are 13984.9; 14924.1; 15033.1; 15204,6; 15371.4; 15538,6; 15705,7; 15872.8; 16040; 16207,1; 16374.2 and 16541.4.

Keywords: Forcasting, Total Tourists and ARIMA Model.

\section{PENDAHULUAN}

Permalan (forcasting) merupakan studi terhadap data historis untuk menemukan hubungan, kecendrungan dan pola data yang sitematis. Peramalan digunakan untuk memprediksi sesuatu yang akan terjadi di masa mendatang sehingga tindakan yang tepat dapat dilakukan. Peramalan menggunakan pendekatan statistik maupun non statistik yang bertujuan untuk meramalkan yang diharapkan mendekati data yang aktual. Peramalan yang dilakukan berdasarkan runtun waktu pada data yang ada sesuai urutan waktu pada priode tertentu.

Kondisi jumlah penduduk yang semakin meningkat dari tahun ke tahun menyebabkan kebutuhan akan wisata semakin besar. Setiap warga negara pasti membutuhkan hiburan untuk melepaskan penat disebabkan kesibukkan dan pekerjaan yang dilakukan setiap hari. Tingginya kebutuhan akan wisata tentu saja perlu dicermati oleh pemerintah dalam menjaga, merawat dan melestarikan obyek wisata guna memberikan kenyamanan bagi para pengunjung. Disadari atau tidak banyaknya pengunjung yang datang ke obyek wisata tergantung pada kenyamanan tempat bagi pengunjung.

Objek wisata yang ada di Toraja Utara diantaranya Objek Wisata Tambalong, Rante Karassik, Buntu Pune, Kete Kesu, Museum Ne' Gandeng, Burakke, Lolai negeri di atas awan dan lain sebagainya. Keberadaan objek wisata tersebut sangat potensial dalam upaya peningkatan pertumbuhan perekonomian sehingga perlu mendapatkan perhatian yang serius dalam memperbaiki kondisi objek wisata yang ada di Toraja Utara. Berdasarkan data dari Dinas Pariwisata Provinsi Sulawesi Selatan Tingkat kunjungan obyek wisata di Toraja Utara terus mengalami peeningkatan dari waktu ke waktu dan paling banyak kunjungan pada bulan Desember karena pada bulan tersebut terdapat event yang sangat spektakuler yang dikenal dengan "lovely Desember".

Jumlah wisatawan yang terus meningkat setiap tahunnya sangat menguntungkan bagi daerah jika diiringi dengan perbaikan sarana dan prasarana yang baik. Namun, bisa menjadi sesuatu yang merugikan bila peningkatan jumlah wisatawan tidak sebanding dengan pelayanan yang kurang memuaskan maka akan mengakibatkan kekecewaan bagi wisatawan baik lokal mapun mancanegara yang dapat mempengaruhi berkurangnya jumlah wisatawan. Bila hal ini terjadi maka dampaknya sangat merugikan bagi Indonesia dan bagi Toraja Utara khususnya sebagai daerah tujuan wisata. Oleh karena itu, agar dapat meningkatkan jumlah wisatawan maka perlu dilakukan perbaikan sarana dan prasarana yang berhubungan dengan tempat pariwisata (Didiharyono and Bakhtiar, 2018).

Salah satu metode yang dapat digunakan dalam mempredisksi jumlah wisatawan di masa mendatang yaitu model ARIMA (Autoregressive Integrated Moving Average). ARIMA merupakan salah satu metode peramalan runtun waktu yang dikembangkan dimana data 


\section{Perkiraan Lonjakan Jumlah Kunjungan Wisatawan di Kabupaten Toraja Utara Tahun 2021 dengan Penerapan Metode ARIMA}

pengamatan dalam sebuah data runtun waktu diasumsikan berhubungan satu sama lain secara statistik. Metode ini dapat digunakan dengan mempelajari pola data pengunjung terdahulu (pada tahun-tahun sebelumnya) dengan memperhatikan konsep tentang stasioner dan nonstasioner, autokovariansi, autokorelasi, autokorelasi parsial, operator backshiff dan operator differensi. Model umum yang mewakili deret waktu yang non-stationer yaitu model ARIMA $(\mathrm{p}, \mathrm{d}, \mathrm{q})$ dimana $\mathrm{p}, \mathrm{d}, \mathrm{q}$ masing-masing adalah orde untuk proses autoregressive, pembedaan (differencing) dan moving average. Model ARIMA (p,d,q) dapat ditulis dalam bentuk umum yaitu (Wei, 2006).

$$
\left(1-\phi_{1} B-\phi_{2} B^{2}-\cdots-\phi_{p} B^{p}\right)(1-B)^{d} \tilde{z}_{t}=\left(1-\theta_{1} B-\cdots-\theta_{q} B^{q}\right) a_{t}
$$

dengan $\phi_{1} \cdots \phi_{p}$ : parameter model AR, (1-B $)^{\mathrm{d}}$ : orde differencing non-musiman, $Z_{t}$ : nilai forecasting periode $t, \theta_{1} \cdots \theta_{q}$ : parameter model MA, $a_{t}$ : residual pada periode $t$.

Analisis time series dengan model ARIMA digunakan dalam peramalan ini karena pola atau keadaan dimasa yang lalu akan berkelanjutan pada masa yang akan datang dan data yang digunakan data tunggal. Metode ini menggunakan pendekatan iteratif dalam mengidentifikasi suatu model yang paling tepat dari semua kemungkinan model yang ada. Kelebihan dari metode ini dapat menangani hampir semua data deret waktu (time series). Penelitian dengan model ARIMA juga digunakan oleh Steve (2014), Eni dan Adeyeye (2015), Wabomba et all (2016), Farhath dkk (2016), Tripathy (2017), Petrevska (2017), Didiharyono dan Bakhtiar (2018) yang fokus penelitiannya pada kasus yang berbeda-beda, tetapi sama mengunakan data time series. Berdasarkan penjelasan di atas maka penelitian ini bertujuan untuk untuk memperkirakan (forecasting) lonjakan jumlah wisatawan di kabupaten Toraja Utara tahun 2021 dengan penerapan model ARIMA. Dalam penelitian tersebut diharapkan dapat memberikan gambaran kepada pemerintah daerah kabupaten mengenai jumlah wisatawan baik wisatawan lokal maupun wisatawan mancanegara yang mengunjungi tempat pariwisata di Toraja Utara pada periode lima tahun mendatang. Sehingga, pemerintah daerah dapat menyediakan pelayanan yang lebih baik dan infrastruktur dalam diperlukan dalam melestarikan obyek wisata guna memberikan kenyamanan bagi para wisatawan serta dapat merumuskan kebijakan yang dapat mempengaruhi peningkatan pertumbuhan ekonomi pada bidang pariwisata.

\section{METODE PENELITIAN}

Jenis penelitian yang digunakan adalah penelitian terapan (applied research) dengan data kuantitatif. Data yang digunakan berupa data kuantitatif bersumber dari Badan Pusat Statistik (BPS) Toraja Utara yang terdiri dari 60 periode mulai Januari 2012 sampai Desember 2016. Prosedur penelitian yang dilakukan yaitu

1. Identifikasi Model meliputi (a). Melakukan plot data asli terhadap waktu. (b). Pemeriksaan kestasioneran data dengan menganalisa plot ACF dan PACF data awal, (c). Ketidakstasioneran diatasi dengan melakukan differensi terhadap data, (d). Menentukan model sementara dengan menganalisa plot ACF dan PACF dari data yang telah stasioner, dan (e). Melakukan Overfitting.

2. Penaksiran dan Pengujian meliputi (a). Menaksir koefisien-koefisien untuk model, (b). Menguji model, dan (c). Pemilihan model yang sesuai dari model sementara. 
3. Tahap verifikasi dan peramalan meliputi (a). Penentuan model MS terkecil, (b). Pemilihan model terbaik dan (c) peramalan.

\section{HASIL DAN PEMBAHASAN}

\section{Identifikasi Model}

Jumlah wisatawan yang datang ke Toraja Utara data bulanan yang disajikan dari Januari 2012 sampai dengan Desember 2016, dimana jumlah periode keseluruhannya yaitu 60 periode (bulan). Berdasarkan data penelitian tersebut maka grafiknya berbentuk,

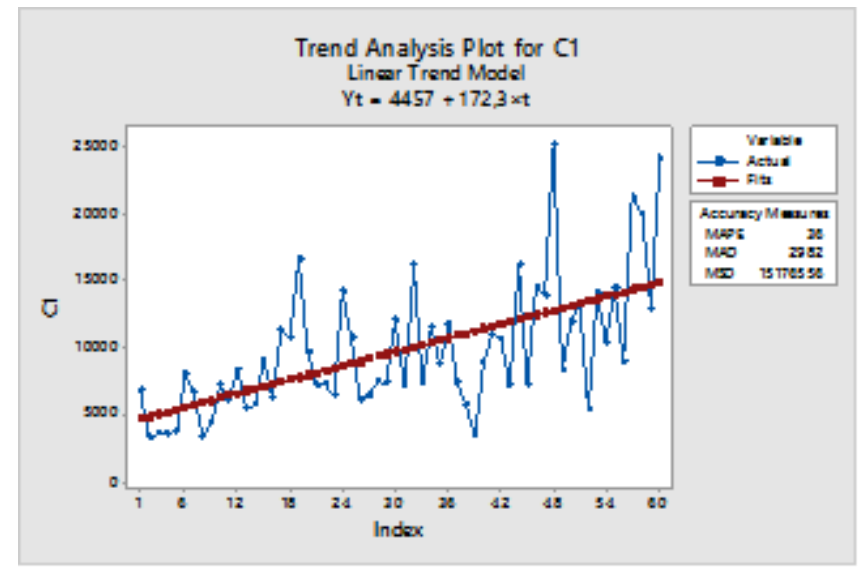

Gambar 1. Model Trend data awal

Berdasarkan plot data dan grafik trend analisis data pada Gambar 1 dapat diketahui bahwa kunjungan wisatawan mengalami peningkatan dengan bertambahnya waktu dan nilai aktualnya masih jauh dari garis linear dan mempunyai varians yang besar, sehingga grafik trend ini termasuk time series yang tidak stasioner dalam rata-rata.

\section{Fungsi Autokorelasi dan Parsial Autokorelasi}

Model peramalan Box-Jenkins diidentifikasi dengan mengamati perilaku dari Autocorrelation Function (ACF) dan Partial Autocorrelation Function (PACF).

Tabel 1. Autocorrelation Function: C1

\begin{tabular}{rrrrrrrr}
\hline Lag & ACF & T & LBQ & Lag & ACF & T & LBQ \\
\hline 1 & 0,307214 & 2,38 & 5,95 & 9 & 0,125557 & 0,70 & 31,80 \\
2 & 0,436412 & 3,10 & 18,17 & 10 & 0,164059 & 0,91 & 33,81 \\
3 & 0,237370 & 1,47 & 21,84 & 11 & 0,101393 & 0,55 & 34,59 \\
4 & 0,198745 & 1,19 & 24,47 & 12 & 0,288579 & 1,56 & 41,04 \\
5 & 0,157979 & 0,92 & 26,16 & 13 & 0,130719 & 0,68 & 42,39 \\
6 & 0,140858 & 0,81 & 27,52 & 14 & 0,099391 & 0,51 & 43,19 \\
7 & 0,210659 & 1,20 & 30,64 & 15 & $-0,057917$ & $-0,30$ & 43,47 \\
8 & $-0,015734$ & $-0,09$ & 30,65 & & & & \\
\hline
\end{tabular}

dengan Grafiknya 


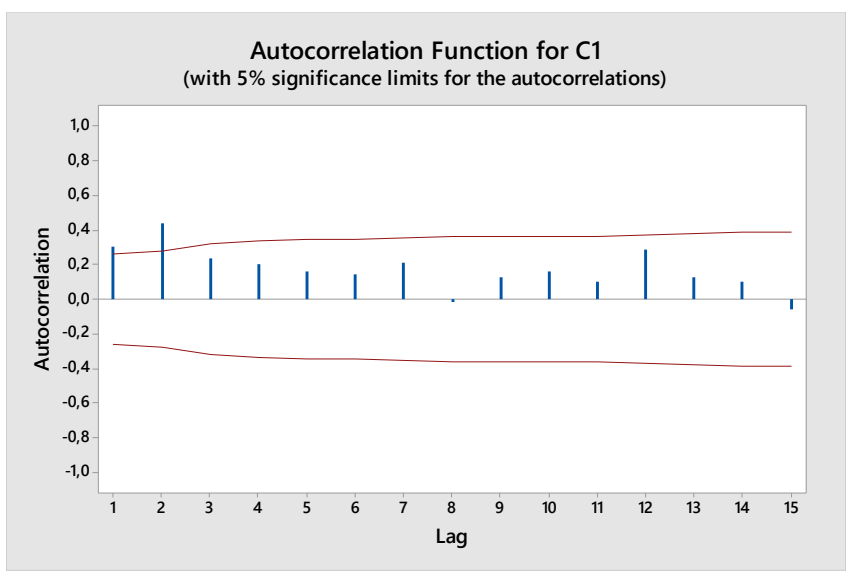

Gambar 2. Grafik ACF

Dari grafik pada Gambar 2 terlihat nilai autokorelasinya turun lambat (berkurang secara perlahan) dan eksponensial sehingga data tersebut belum stasioner sehingga tidak terbentuk model.

Tabel 2. Partial Autocorrelation Function: C1

\begin{tabular}{cccccc}
\hline Lag & PACF & T & Lag & PACF & T \\
\hline 1 & 0,307214 & 2,38 & 9 & 0,027281 & 0,21 \\
2 & 0,377677 & 2,93 & 10 & 0,233022 & 1,80 \\
3 & 0,048821 & 0,38 & 11 & $-0,008951$ & $-0,07$ \\
4 & $-0,023249$ & $-0,18$ & 12 & 0,181076 & 1,40 \\
5 & 0,023299 & 0,18 & 13 & $-0,044946$ & $-0,35$ \\
6 & 0,042569 & 0,33 & 14 & $-0,165519$ & $-1,28$ \\
7 & 0,140590 & 1,09 & 15 & $-0,139294$ & $-1,08$ \\
8 & $-0,190121$ & $-1,47$ & & & \\
\hline
\end{tabular}

dengan Grafiknya

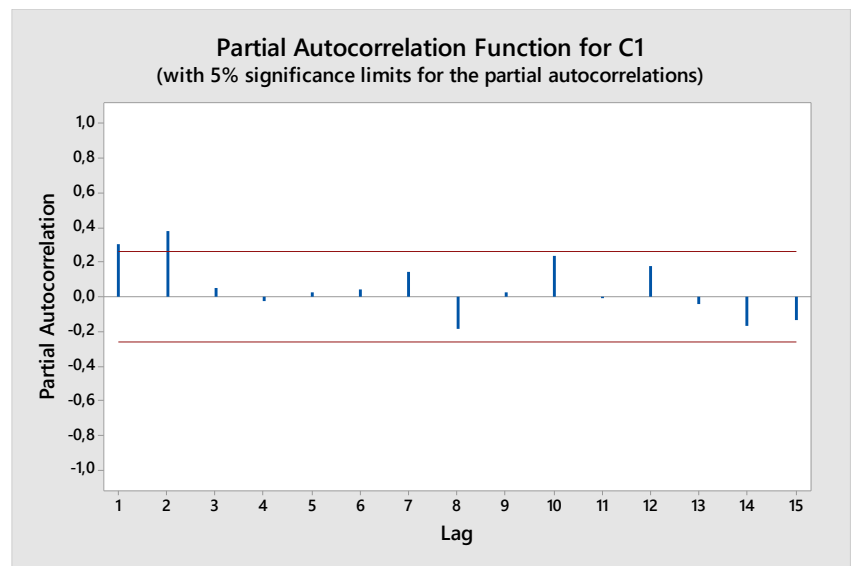

Gambar 3. Grafik PACF

Grafik PACF data asli pada pada Gambar 3 juga belum stasioner stasioner, karena nilai autokorelasi PACF masih terlihat turun lambat dan terputus pada lag-2. Pada gambar 2 dan 
gambar 3 menunjukan 15 lag, dalam minitab apabila banyaknya lag maka secara otomatis akan menampakan lag sebanyak pengamatan $(\mathrm{n}) \leq 240$, dalam hal ini jumlah pengamatan adalah 60 sehingga $60 / 4=15$ lag. Pada identifikasi data asli ini belum terbentuk model sehingga diperlukan data selisih pertama untuk menstasionerkan data tersebut.

\section{Differences Data}

Berdasarkan Gambar 1 menunjukan data belum stationer, maka dilakukan dilakukan differences pertama sehingga bentuk grafiknya adalah sebagai berikut.

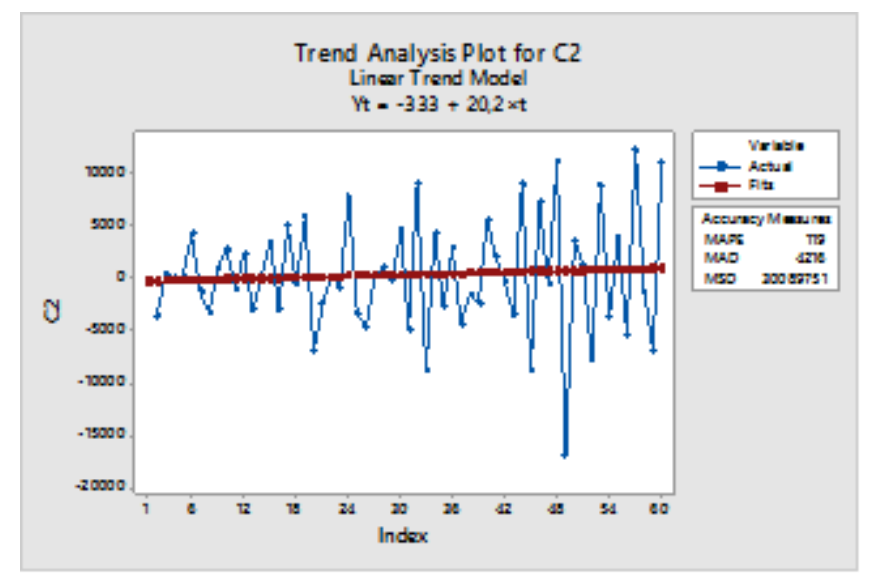

Gambar 4. Grafik Analisis Data setelah differences

Dari plot analisis data selisih pertama pada Gambar 4 dapat dilihat data sudah stasioner, karena rata-rata jumlah produksi tidak bergerak bebas dalam suatu waktu tertentu dan memiliki variansi cukup kecil dan nilai aktualnya sudah mendekati garis linear. Selanjutnya ditentukan nilai ACF dan PACF yaitu:

Tabel 3. Autocorrelation Function: C2

\begin{tabular}{cccccccc}
\hline Lag & ACF & T & LBQ & Lag & ACF & T & LBQ \\
\hline 1 & $-0,583944$ & $-4,49$ & 21,16 & 9 & 0,022673 & 0,12 & 32,67 \\
2 & 0,207337 & 1,23 & 23,87 & 10 & 0,089134 & 0,48 & 33,26 \\
3 & $-0,143279$ & $-0,83$ & 25,19 & 11 & $-0,170054$ & $-0,91$ & 35,43 \\
4 & 0,099848 & 0,57 & 25,85 & 12 & 0,134973 & 0,72 & 36,82 \\
5 & $-0,057667$ & $-0,33$ & 26,07 & 13 & $-0,013395$ & $-0,07$ & 36,84 \\
6 & $-0,040970$ & $-0,23$ & 26,18 & 14 & 0,101033 & 0,53 & 37,65 \\
7 & 0,202860 & 1,15 & 29,03 & 15 & $-0,194405$ & $-1,02$ & 40,74 \\
8 & $-0,226139$ & $-1,25$ & 32,64 & & & & \\
\hline
\end{tabular}


dengan Grafiknya

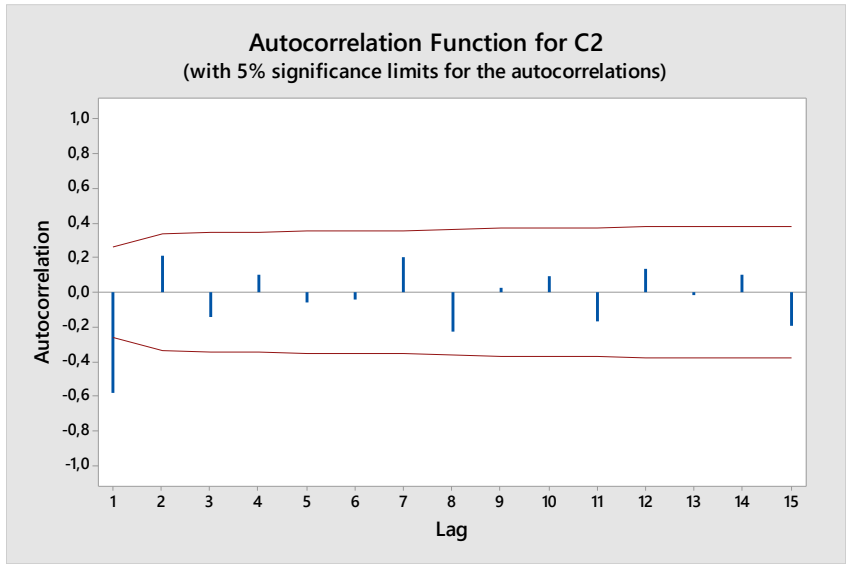

Gambar 5. Grafik ACF setelah differences

Tabel 4. Partial Autocorrelation Function: C2

\begin{tabular}{cccccc}
\hline Lag & PACF & T & Lag & PACF & T \\
\hline 1 & $-0,583944$ & $-4,49$ & 9 & $-0,210378$ & $-1,62$ \\
2 & $-0,202811$ & $-1,56$ & 10 & 0,012618 & 0,10 \\
3 & $-0,183700$ & $-1,41$ & 11 & $-0,224872$ & $-1,73$ \\
4 & $-0,073036$ & $-0,56$ & 12 & $-0,125367$ & $-0,96$ \\
5 & $-0,044219$ & $-0,34$ & 13 & 0,069911 & 0,54 \\
6 & $-0,145297$ & $-1,12$ & 14 & 0,127356 & 0,98 \\
7 & 0,173266 & 1,33 & 15 & 0,005761 & 0,04 \\
8 & $-0,006961$ & $-0,05$ & & & \\
\hline
\end{tabular}

dengan Grafiknya,

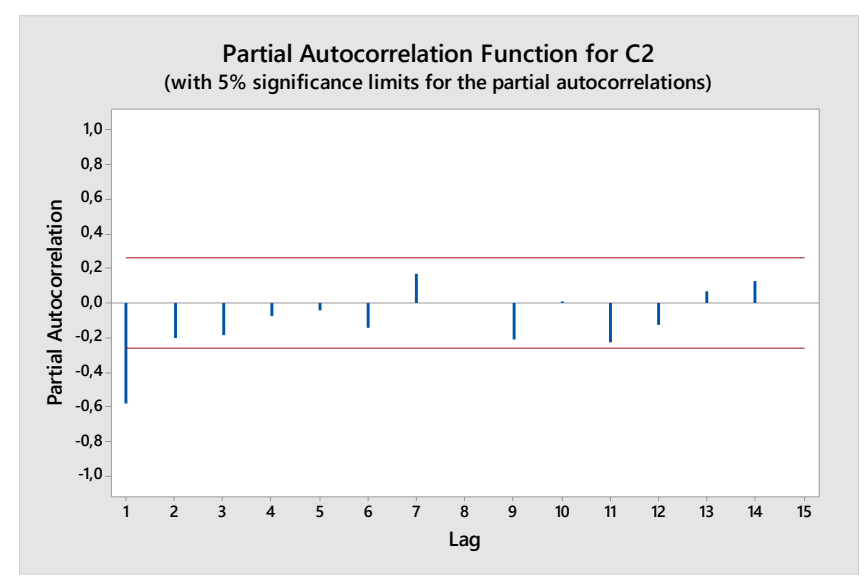

Gambar 6. Grafik PACF setelah differences

Dari grafik ACF pada gambar 5 terlihat data sudah stasioner karena grafiknya turun lambat (dies down) sehingga dapat langsung diperkirakan modelnya dan nilai $\rho_{k}$ memotong (cut off) garis white noise pada lag-1 atau lag-q untuk tingkat moving average tertinggi. Sedangkan dari 
grafik PACF pada Gambar 6 terlihat mengikuti grafik sinus dan grafiknya turun (dies down) secara eksponensia. Dengan melihat kedua grafik diatas dapat terlihat nilai $\rho_{k}$ memotong ( $c u t$ off) garis white noise pada lag ke-1, sedangkan $\phi_{k k}$ memotong white noise pada lag-1. Sehingga perkiraan modelnya adalah ARIMA $(1,1,1)$ atau AR (1) karena grafik ACF turun secara eksponensial dan PACF terputus pada lag-1, differences 1 kali, MA(1) karena grafik ACF terputus pada lag-1 dan PACF turun secara ekspoensial (sinusoidal), sehingga bentuk umum dapat ditulis:

$$
Z_{t}=\left(1+\phi_{1}\right) Z_{t-1}-\phi_{1} Z_{t-2}+a_{t}-\theta_{1} a_{t-1}
$$

Serta menungkinkan juga estimasi modelnya adalah ARIMA $(2,1,1)$ atau AR (2) karena grafik ACF turun secara eksponensial dan PACF terputus pada lag-2, differences $1 \mathrm{kali}$, MA(1) karena grafik ACF terputus pada lag-1 dan PACF turun secara ekspoensial (sinusoidal), sehingga bentuk umum dapat ditulis:

$$
Z_{t}=\left(1+\phi_{1}\right) Z_{t-1}+\left(\phi_{2}-\phi_{1}\right) Z_{t-2}-\phi_{2} Z_{t-3}+a_{t}-\theta_{1} a_{t-1}
$$

Selanjutnya, dilakukan differences kedua dengan tujuan melihat perbandingan antara nilai Mean Square dengan hasil differences yang pertama. Sebagai perbandingan nilai MS, bisa juga diperkirakan modelnya yaitu ARIMA $(1,2,1)$ bila dilakukan defferences yang ke-2. ARIMA $(1,2,1)$ dengan bentuk umumnya yaitu:

$$
Z_{t}=\left(2+\phi_{1}\right) Z_{t-1}-\left(1+2 \phi_{1}\right) Z_{t-2}+\phi_{1} Z_{t-3}+a_{t}-\theta_{1} a_{t-1}
$$

\section{Estimasi Parameter dalam Model}

Setelah melakukan identifikasi data maka langkah selanjutnya yaitu melakukan estimasi parameter. Hasil output yang diperoleh dengan menggunakan Software Minitab yaitu

\section{Model ARIMA $(1,1,1)$}

Dari hasil penghitungan diperoleh model ARIMA $(1,1,1)$ yang mempunyai parameter dari $\phi_{1}=-0,075$ dan $\theta_{1}=0,9830$. Maka diperoleh persamaan modelnya yaitu:

$$
\begin{gathered}
Z_{t}=\left(1+\phi_{1}\right) Z_{t-1}-\phi_{1} Z_{t-2}+a_{t}-\theta_{1} a_{t-1} \\
Z_{t}=(1-0,075) Z_{t-1}+0,075 Z_{t-2}+a_{t}-0,9830 a_{t-1} \\
Z_{t}=0,925 Z_{t-1}+0,075 Z_{t-2}+a_{t}-0,9830 a_{t-1}
\end{gathered}
$$

dengan nilai error atau nilai MS (Mean Square) pada data selisih pertama ini adalah 16487384.

\section{Model ARIMA $(2,1,1)$}

Dari hasil penghitungan diperoleh model $\operatorname{ARIMA}(2,1,1)$ yang mempunyai parameter dari $\phi_{1}=-0,053, \phi_{2}=0,254, \theta_{1}=0,734$. Maka diperoleh persamaan modelnya yaitu:

$$
\begin{gathered}
Z_{t}=\left(1+\phi_{1}\right) Z_{t-1}+\left(\phi_{2}-\phi_{1}\right) Z_{t-2}-\phi_{2} Z_{t-3}+a_{t}-\theta_{1} a_{t-1} \\
Z_{t}=(1-0,053) Z_{t-1}+(0,254+0,053) Z_{t-2}-0,254 Z_{t-3}+a_{t}-0,734 a_{t-1} \\
Z_{t}=0,947 Z_{t-1}+0,307 Z_{t-2}-0,254 Z_{t-3}+a_{t}-0,734 a_{t-1}
\end{gathered}
$$

dengan nilai error atau MS (Mean Square) pada data selisih pertama ini adalah 18046150. 


\section{Model ARIMA $(1,2,1)$}

Dari hasil penghitungan di atas diperoleh model ARIMA $(1,2,1)$ yang mempunyai parameter dari $\phi_{1}=-0,681$ dan $\theta_{1}=1,0411$. Maka diperoleh persamaan modelnya yaitu:

$$
\begin{gathered}
Z_{t}=\left(2+\phi_{1}\right) Z_{t-1}-\left(1+2 \phi_{1}\right) Z_{t-2}+\phi_{1} Z_{t-3}+a_{t}-\theta_{1} a_{t-1} \\
Z_{t}=(2-0,681) Z_{t-1}-(1+2(-0,681)) Z_{t-2}-0,681 Z_{t-3}+a_{t}-1,0411 a_{t-1} \\
Z_{t}=1,319 Z_{t-1}+0,362 Z_{t-2}-0,681 Z_{t-3}+a_{t}-1,0411 a_{t-1}
\end{gathered}
$$

dengan nilai error atau MS (Mean Square) pada data selisih pertama ini adalah 19491948.

\section{Verifikasi dan Peramalan}

Pada tahap ini bertujuan untuk memeriksa model yang terbaik yaitu dengan cara mencari nilai MS (Mean Square) terkecil berdasarkan hasil estimasi parameter sebagaimana dalam lampiran 2 yaitu sebagai berikut:

- $\quad$ Model ARIMA $(1,1,1)$ mempunyai nilai MS sebesar 16487384

- Model ARIMA $(2,1,1)$ mempunyai nilai MS sebesar 18046150

- $\quad$ Model ARIMA (1,2,1) mempunyai nilai MS sebesar 19491948

Dari keempat model ARIMA tersebut dapat disimpulkan bahwa model ARIMA $(1,1,1)$ yang mempunyai nilai MS terkecil. Dengan demikian model yang tepat untuk meramalkan data wisatawan adalah model ARIMA $(1,1,1)$ dengan persamaan umum berikut.

$$
Z_{t}=0,925 Z_{t-1}+0,075 Z_{t-2}+a_{t}-0,9830 a_{t-1}
$$

Model ARIMA $(1,1,1)$ adalah model yang paling cocok untuk memodelkan data deret waktu dan meramalkan periode kedepan dari data jumlah wisatawan yang datang mengunjungi tempat Pariwisata di Toraja. Adapun hasil peramalannya yaitu:

Tabel 5. Forecasts from period 60

\begin{tabular}{ccccc}
\hline & \multicolumn{4}{c}{ 95\% Limits } \\
Period & Forecast & Lower & Upper & Actual \\
\hline 61 & 13984,9 & 6024,75 & 21945,0 & \\
62 & 14924,1 & 6950,43 & 22897,7 & \\
63 & 15033,1 & 7057,60 & 23008,5 & \\
64 & 15204,6 & 7228,18 & 23181,0 & \\
65 & 15371,4 & 7393,99 & 23348,8 & \\
66 & 15538,6 & 7560,17 & 23516,9 & \\
67 & 15705,7 & 7726,31 & 23685,1 & \\
68 & 15872,8 & 7892,46 & 23853,2 & \\
69 & 16040,0 & 8058,61 & 24021,3 & \\
70 & 16207,1 & 8224,76 & 24189,5 & \\
71 & 16374,2 & 8390,91 & 24357,6 & \\
72 & 16541,4 & 8557,06 & 24525,7 & \\
\hline
\end{tabular}


Tabel forcast di atas menunjukan bahwa untuk periode (t) setelah 60 bulan yang akan datang yaitu pada bulan Januari sampai Desember Tahun 2021 terjadi peningkatan yang cukup signifikan setiap bulan dengan data $95 \%$ batas bawah dan batas atas data actual.

\section{KESIMPULAN}

Berdasarkan hasil analisis di atas dapat diperoleh simpulan yaitu sebagai berikut.

1. Berdasarkan hasil penelitian diperoleh empat model time series yang digunakan dalam melakukan forcasting jumlah wisatawan di Toraja di masa mendatang yakni ARIMA $(1,1,1)$, ARIMA $(2,1,1)$ dan ARIMA $(1,2,1)$. Dalam pemilihan model yang baik adalah model yang mempunyai nilai MS (Mean Square) terkecil. Dalam hal ini model time series dengan MS terkecil adalah ARIMA $(1,1,1)$ yaitu sebesar 16487384 . Sehingga model yang digunakan dalam melakukan peramalan adalah ARIMA $(1,1,1)$, dengan bentuk umumnya yaitu:

$$
Z_{t}=0,925 Z_{t-1}+0,075 Z_{t-2}+a_{t}-0,9830 a_{t-1}
$$

2. Hasil forcasting jumlah wisatawan di Toraja Utara dari bulan januari sampai Desember 2021 adalah 13984,9; 14924,1; 15033,1; 15204,6; 15371,4; 15538,6; 15705,$7 ; 15872,8 ; 16040 ; 16207,1 ; 16374,2$ dan 16541,4 .

\section{DAFTAR PUSTAKA}

Aswi dan Sukarna. 2008. Analisis Deret Waktu, Teori dan Aplikasi. Makassar: Andhira Publisher.

Didiharyono and Bakhtiar. 2018. Forecasting Model With Box-Jenkins Method To Predict Tourists Who Visit Tourism Place In Toraja. Journal of Economic, Management and Acounting. 1(1): 62-71.

Eni, Daniel and Fola J. Adeyeye. 2015. Seasonal ARIMA Modeling and Forecasting of Rainfall in Warri Town, Nigeria. Journal of Geoscience and Environment Protection. Vol. 3: 91-98

Farhath, Z. A., at. all. 2016. A Survey On Arima Forecasting Using Time Series Model. International Journal of Computer Science and Mobile Computing. Vol.5 Issue.8: 104-109.

Petrevska, Biljana. 2017. Predicting tourism demand by A.R.I.M.A models. Economic Research-Ekonomska Istraživanja. 30(1): 939-950.

Steve, Nwankwo. 2014. Autoregressive Integrated Moving Average (ARIMA) Model for Exchange Rate (Naira to Dollar). Academic Journal of Interdisciplinary Studies. 3(4): 429-433.

Tripathy, Naliniprava. 2017. Forecasting Gold Price with Auto Regressive Integrated Moving Average Model. International Journal of Economics and Financial Issues. 7(4), 324-329.

Wabomba, M.S., et all. 2016. Modeling and Forecasting Kenyan GDP Using Autoregressive Integrated Moving Average (ARIMA) Models. Science Journal of Applied Mathematics and Statistics. 4(2): 64-73.

Wei, William WS. 2006. Time Series Analysis. New York: Pearson Addison Wesley. 